\title{
EFFECTS OF HOT PRESSING PARAMETERS ON THE PROPERTIES OF HARDBOARDS PRODUCED FROM MIXED HARDWOOD TREE SPECIES
}

\author{
Petar Antov, Viktor Savov, Nikolay Neykov \\ University OF Forestry \\ BULGARIA \\ L'uboš KrišŤÁk \\ Technical University In Zvolen \\ SLOVAKIA \\ (Received September 2020)
}

\begin{abstract}
In this work, wet-process fibreboards (hardboards) were produced in the laboratory using industrial wood fibres of the species European beech (Fagus sylvatica L.) and Turkey oak (Quercus cerris L.) at the total volume of 40\%, and white poplar (Populus alba L.) at $60 \%$ volume. The effects of hotpressing pressure (variedfrom 3.3 MPa to 5.3 MPa) and pressing time (from $255 \mathrm{~s}$ to $355 \mathrm{~s}$ ) on the physical and mechanical properties of hardboards were investigated and optimal values of the parameters for fulfilling the European standard requirements were determined. It was concluded that hardboards with acceptable physical and mechanical properties may be produced from $60 \%$ poplar wood waste and residues, combined with $40 \%$ hardwood raw materials (beech and oak) by regulating the hot pressing regime only, i.e. pressure and pressing time. The following minimum parameters for producing hardboards from mixed hardwood tree species were determined: a pressure of $4.6 \mathrm{MPa}$ and a pressing time of $280 \mathrm{~s}$.
\end{abstract}

KEYWORDS: Wood composites, fibreboards, hardboards, mixed hardwood raw material, hot pressing. 


\section{INTRODUCTION}

The growing need for more sustainable materials and final products and the stricter legislative requirements related to the hazardous formaldehyde emissions from wood-based panels have boosted the scientific and industrial interest towards the production of eco-friendly wood-based composites (Pizzi 2006, Papadopoulou 2009, Ferdosian et al. 2017, Nordström et al. 2017, Mantanis et al. 2018, Bekhta and Sedliačik 2019, Hosseinpourpia et al. 2019, Antov et al. 2020a, Santoso et al. 2020, Papadopoulos 2020a, Taghiyari et al. 2020, Tudor et al. 2020a, Antov et al. 2021a, Antov et al. 2021b, Antov et al. 2021c) and optimal utilization of the available lignocellulosic materials (Ihnát et al. 2015, Réh et al. 2019, Bekhta et al. 2019, Kumar and Pizzi 2019, Lubke et al. 2020, Papadopoulos 2020b, Tudor et al. 2020b, Rammou et al. 2021). Fibreboards, produced by the wet process, are an eco-friendly flat-pressed wood composite panels, consisting of lignocellulosic fibres traditionally bonded without any adhesive by hot-pressing (González-García et al. 2014, Widsten and Kandelbauer 2014, Pizzi 2017). Fibre bonding is achieved by the high density $\left(900-1100 \mathrm{~kg} \cdot \mathrm{m}^{-3}\right.$ ) and the high-temperature induced flow of the lignin component of the fibres (Pizzi et al. 2020). These engineered wood panels are characterized by homogeneous thickness, density, uniform appearance and no grain (Widsten et al. 2009). Additives such as paraffin wax can be used to improve certain properties such as abrasion and water resistance (González-García et al. 2011).

Another important advantage of these wood-based panels is the increased utilization of small-sized low quality wood of hardwood tree species, which is otherwise used mainly for energy purposes (Trichkov and Antov 2005, Shulga et al. 2016, Schneider et al. 2019). Despite the high quantitative output, wet process fibreboards have certain disadvantages, namely the presence of small percentage of phenolic binder which hinders the recycling and disposal of hardboards (Smith 2004, González-García et al. 2014, Lubis et al. 2018a, Lubis et al. 2020), and the low added value of the final product (Neykov et al. 2018).

A good solution to overcome this problem are factories producing more than one type of wood-based panels (Neykov et al. 2014), such as the company Welde Bulgaria AD (Troyan, Bulgaria), producing hardboards and plywood. The plywood production technology is characterised by the lowest quantitative output of all technologies for production of wood-based composites. The main raw material used in this company is poplar (Populus spp.) and the production process is characterized by considerable amounts of wood waste and leftover materials, which can be further utilized in the production of hardboards. Fibre composites allow the utilization of waste and residues from other processing industries, such as pulp and paper industry (Russ et al. 2013, Tikhonova et al. 2014, Bajpai 2015, Lubis et al. 2018b, Ihnát et al. 2018, Ihnát et al. 2020, Antov et al. 2020a, Antov et al. 2021a). Optimising the utilization of waste wood from the production of plywood will have a significant environmental impact and will enhance the competitiveness of the respective companies (Neykov et al. 2020a, Neykov et al. 2020b). The increased utilization of poplar requires changes in the technological regimes used for the production of hardboards. The hot pressing regime applied is of great importance for engineering the hardboard properties (Carvalho and Costa 2003, Gupta 2007, Gul et al. 2017). This also applies to the production of wet process fibreboards, where the adhesive bonds perform mainly a stabilizing function.

The aim of the research work was to investigate the effect of hot pressing parameters, i.e. pressure and pressing time on the physical and mechanical properties of hardboards produced from mixed hardwood raw materials. 


\section{MATERIAL AND METHODS}

Hardboard were produced in the laboratory using industrial wood-fibre mat, supplied by Welde Bulgaria AD (Troyan, Bulgaria), and composed of the following tree species: European beech (Fagus sylvatica L.) and Turkey oak (Quercus cerris L.) at the total volume of $40 \%$, and white poplar (Populus alba L.) at $60 \%$ volume. The phenol-formaldehyde resin content was $0.5 \%$, based on the dry weight of the fibres. The pulp freeness was 16.98 Ds (Defibrator seconds), as the result of the significant quantity of poplar wood. The wood fibre mass was obtained in factory conditions according to the Asplund method by using the L46 Defibrator (Sweden) equipment. The dry content of the mat was 25\%. The hot pressing pressure was varied from 3.3 to $5.3 \mathrm{MPa}$, and the pressing time from 255 to $375 \mathrm{~s}$, respectively. These values were selected in accordance with the factory regimes used for production of hardboards (a pressure of $4.3 \mathrm{MPa}$ and a pressing time of $315 \mathrm{~s}$ ). The press temperature used was $200^{\circ} \mathrm{C}$. Hot pressing was performed in a laboratory press (Defibrator, Sweden) with dimensions of the platens $480 \times 480 \mathrm{~mm}$. The physical and mechanical properties of the hardboards were determined according to European standards EN 310, EN 317, EN 319, EN 322 and EN 323 (European Committee for Standardization). The following physical properties of the hardboards were investigated: density, water absorption and thickness swelling. Thickness swelling and water absorption tests were carried out for $24 \mathrm{~h}$. The mechanical properties of the hardboards produced, i.e. modulus of elasticity (MOE), bending strength (MOR) and internal bond strength, were determined using a universal-material testing machine Zwick/Roell Z010 (Zwick/Roell GmbH, Ulm, Germany). Variational and statistical analyses of the results were carried out by using the specialised software QstatLab version 6.0.

\section{RESULTS AND DISCUSSION}

A summary of the physical and mechanical properties of the laboratory-produced hardboard panels at different hot pressing parameters (pressure and pressing time) is shown in Tab. 1 and Tab. 2, respectively. The thickness of the hardboards varied from 2.2 to $2.8 \mathrm{~mm}$.

Tab. 1: Physical properties of the laboratory-produced hardboards.

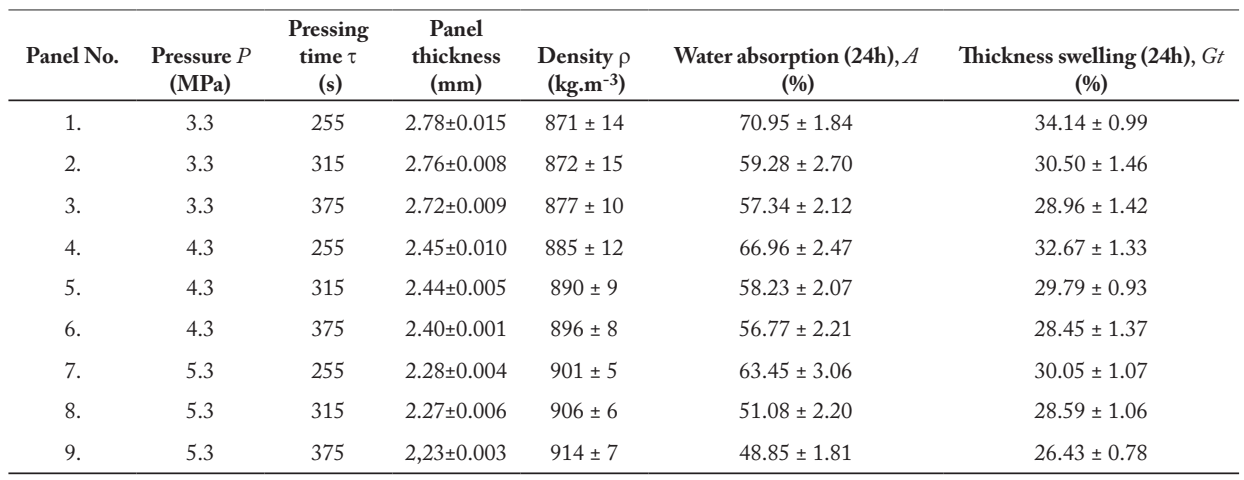


Tab. 2: Mechanical properties of the laboratory-produced hardboards.

\begin{tabular}{|c|c|c|c|c|c|}
\hline Panel No. & $\begin{array}{l}\text { Pressure } P, \\
\text { (MPa) }\end{array}$ & $\begin{array}{c}\text { Pressing } \\
\text { time } \tau \text {, } \\
\text { (s) }\end{array}$ & $\begin{array}{c}\text { Modulus of elasticity (MOE), } \\
E m, \\
\left(\mathrm{~N} \cdot \mathrm{mm}^{-2}\right)\end{array}$ & $\begin{array}{c}\text { Bending strength (MOR), } \\
\text { fm, } \\
\left(\mathrm{N} \cdot \mathrm{mm}^{-2}\right)\end{array}$ & $\begin{array}{c}\text { Internal bond strength } \\
f t, \\
\left(\mathrm{~N} \cdot \mathrm{mm}^{-2}\right)\end{array}$ \\
\hline 1. & 3.3 & 255 & $2239 \pm 71$ & $30.44 \pm 0.89$ & $0.48 \pm 0.02$ \\
\hline 2. & 3.3 & 315 & $2249 \pm 63$ & $33.01 \pm 0.62$ & $0.55 \pm 0.02$ \\
\hline 3. & 3.3 & 375 & $2300 \pm 39$ & $33.77 \pm 0.52$ & $0.58 \pm 0.02$ \\
\hline 4. & 4.3 & 255 & $2344 \pm 35$ & $33.30 \pm 0.53$ & $0.52 \pm 0.03$ \\
\hline 5. & 4.3 & 315 & $2558 \pm 77$ & $36.04 \pm 0.68$ & $0.57 \pm 0.03$ \\
\hline 6. & 4.3 & 375 & $2541 \pm 47$ & $36.53 \pm 0.86$ & $0.59 \pm 0.01$ \\
\hline 7. & 5.3 & 255 & $2586 \pm 46$ & $36.63 \pm 0.72$ & $0.53 \pm 0.01$ \\
\hline 8. & 5.3 & 315 & $2581 \pm 19$ & $39.55 \pm 0.36$ & $0.67 \pm 0.03$ \\
\hline 9. & 5.3 & 375 & $2599 \pm 64$ & $36.76 \pm 1.02$ & $0.66 \pm 0.03$ \\
\hline
\end{tabular}

A graphical representation of the effects of hot pressing pressure and pressing time on the density of the fibreboards is presented in Fig. 1.

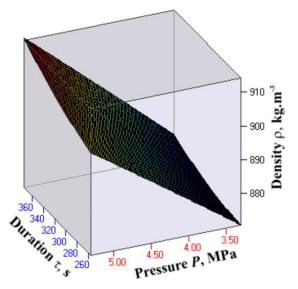

a)

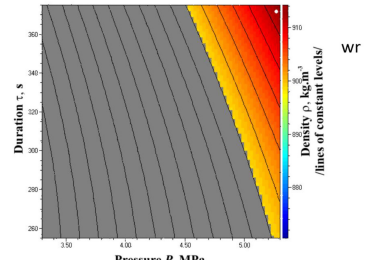

b)

Fig. 1: Variation of the density of hardboard panels depending upon the pressing time (duration) and pressure applied: a) explicit form, and b) optimal value.

The density of the laboratory-produced fibreboards varied from 871 to $914 \mathrm{~kg} \cdot \mathrm{m}-3$, hence the variation of the density was $7 \%$. Both studied factors had a positive effect on the density of the panels, i.e. increasing the pressure from 3.3 to $5.3 \mathrm{MPa}$ and pressing time fr om 255 to $374 \mathrm{~s}$, respectively, resulted in higher density values of the fabricated fibreboards. Statistically, the dependence of the density upon both factors is very close to linear. Pressure had almost three times higher effect on the density compared to the pressing time applied. As seen in Fig. 1b, the optimal (maximum) density of the panels of $914 \mathrm{~kg} \cdot \mathrm{m}-3$ was obtained at the upper limit factor values. A limitation, i.e. density greater than $900 \mathrm{~kg} . \mathrm{m}-3$, required for producing hardboards, was also set (EN 316). As seen in Fig. 1, hardboards can be fabricated from wood-fibre mass, composed of $60 \%$ poplar wood and $40 \%$ hardwood species (European beech and Turkey oak) at hot pressing pressure of $5.3 \mathrm{MPa}$ and pressing time of $255 \mathrm{~s}$. Hence, the highest output (minimum pressing time) can be achieved at a pressure of at least 5.3 $\mathrm{MPa}$. The minimum pressure for producing hardboards was 4.6 $\mathrm{MPa}$ and the pressing time - at least $375 \mathrm{~s}$. A graphical representation of the effects of pressure and pressing time on the modulus of elasticity (MOE) of the fabricated panels is presented in Fig. 2.

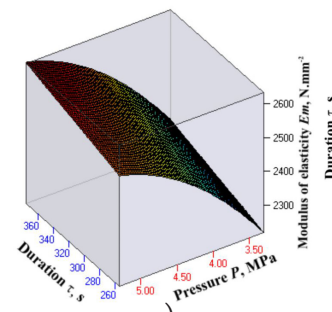

a)

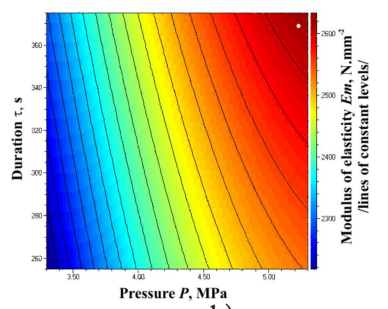

b)

Fig. 2: Variation of the modulus of elasticity (MOE) of hardboard panels depending upon the pressing time (duration) and pressure applied: a) explicit form and b) optimal value. 
The MOE of the produced fibreboards improved with the increase of pressure and pressing time. Within the limitations of the experiment the overall improvement of this indicator was $16 \%$. The effect of pressure was of the second degree, with greater improvement observed when the pressure was increased to $4.5 \mathrm{MPa}$. The dependence of the $\mathrm{MOE}$ of the laboratory-produced panels on the pressing time was similar to linear. The pressure had greater effect on the MOE values compared to the pressing time. None of the panels met the standard requirements for fibreboards - use in load-bearing applications $\left(\geq 2700 \mathrm{~N} . \mathrm{mm}^{-2}\right)(\mathrm{EN} \mathrm{622-2})$. The maximum $\mathrm{MOE}$ value was obtained for fibreboards produced at a pressure of 5.3 $\mathrm{MPa}$ and pressing time of 370 s, i.e. close to the upper limit factor values. A graphical representation of the effects of pressure and pressing time on the bending strength (MOR) of the fibreboards is shown in Fig. 3.

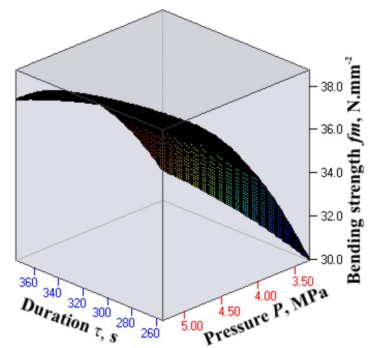

a)

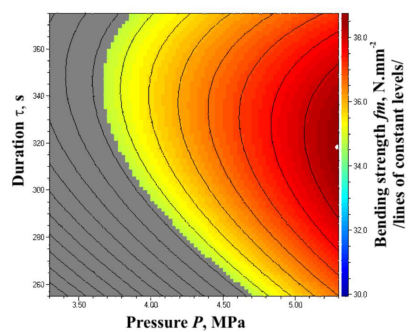

b)

Fig. 3: Variation of the bending strength (MOR) of hardboard panels depending upon the pressing time (duration) and pressure applied: a) explicit form, and b) optimal value.

The increase of pressure applied resulted in increased bending strength (MOR) values of the laboratory-produced panels. Regarding the effect of pressing time on MOR values, it was determined that increasing the pressing time up to $320 \mathrm{~s}$ resulted in improved bending strength values, while further increase of pressing time resulted in lower values of the studied indicator. This might be attributed to the initial destructive processes of wood components, occurring due to the extended pressing time. The variation of the MOR values of the produced panels within the standard requirement $\left(\geq 35 \mathrm{~N} \cdot \mathrm{mm}^{-2}\right)$ for fibreboards with general application is presented in Fig. 3b. The maximum MOR strength, recorded in this work, i.e. $38.72 \mathrm{~N} \cdot \mathrm{mm}^{-2}$, was realised at a pressure of $5.3 \mathrm{MPa}$ and a pressing time of $318 \mathrm{~s}$. A graphical representation of the effects of pressure and pressing time applied on the internal bond strength of fibreboards produced is presented analytically in Fig. 4.

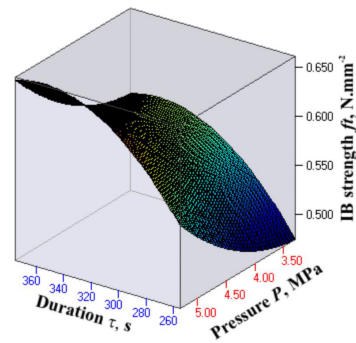

a)

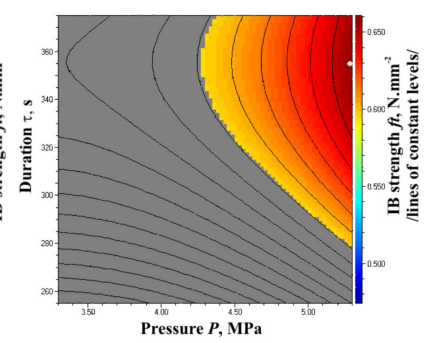

b)

Fig. 4: Variation of the internal bond strength of hardboard panels depending upon the pressing time (duration) and pressure applied: a) explicit form, and b) optimal value. 
The increased pressure and extended pressing time resulted in improved IB strength of the laboratory-produced fibreboards. The effect of pressure increased significantly above the value of 4.5 MPa. The pressing time had a stronger effect when extended to $340 \mathrm{~s}$, followed by constant values of the studied indicator. The variation of the IB strength values of the produced panels within the standard requirement $\left(\geq 0.5 \mathrm{~N} \cdot \mathrm{mm}^{-2}\right)$ for fibreboards with general application in dry conditions (EN 622-2) is presented in Fig. 4b. The standard requirement can be achieved at pressure values of at least $4.3 \mathrm{MPa}$ and pressing time of at least $280 \mathrm{~s}$. According to the statistical analysis, the optimal value of $0.68 \mathrm{~N} \cdot \mathrm{mm}^{-2}$ for IB strength was projected at a pressure of $5.3 \mathrm{MPa}$ and 355 s pressing time. A graphical representation of the effects of pressure and pressing time on the thickness swelling of fibreboards is presented in Fig. 5.

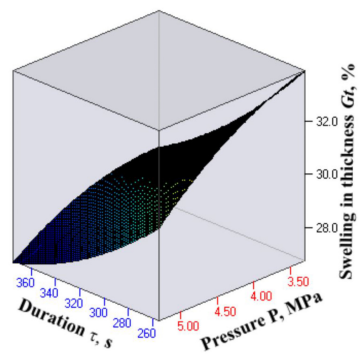

a)

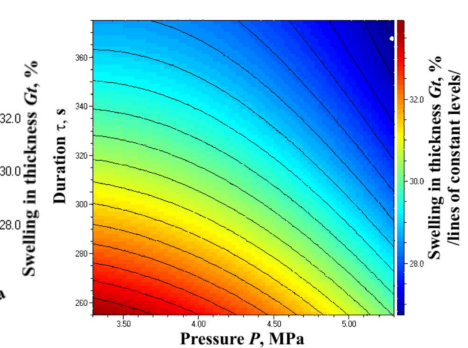

b)

Fig. 5: Variation of the thickness swelling of hardboard panels depending upon the pressing time (duration) and pressure applied: a) explicit form, and b) optimal value.

Thickness swelling (TS) and water absorption (WA) are critical physical properties, related to the dimensional stability of wood-based composites (Youngquist 1999, Frihart 2005). The variation of TS values of the fabricated panels was 1.29 times. All laboratory-fabricated panels met the standard requirement for hardboards - general application in dry conditions $(\mathrm{TS} \leq 35 \%)$ (EN 622-3). The standard requirement for general application in humid environment (TS $\leq 25 \%)$ was not achieved. The increased pressure values resulted in improved (lower) TS values, as the most significant improvement was determined at pressure values above 4.25 $\mathrm{MPa}$. Extending the pressing time up to $340 \mathrm{~s}$ resulted in relatively gradual improvement of the TS values. The optimal TS value (26.33\%) of the panels, produced in this work, can be achieved at a pressure of $5.3 \mathrm{MPa}$ and a pressing time of $366 \mathrm{~s}$. A graphical representation of the effects of pressure and pressing time on the WA of the laboratory-made panels is presented in Fig. 6.

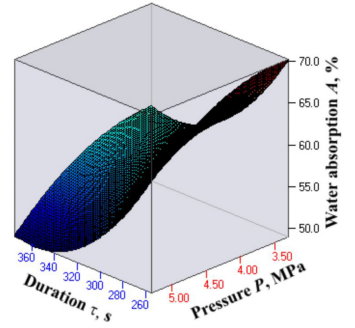

a)

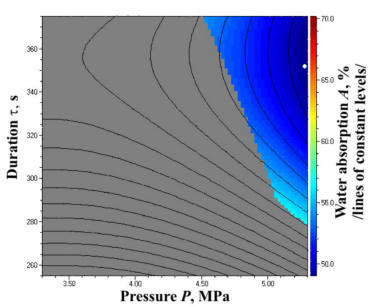

b)

Fig. 6: Variation of the water absorption of hardboard panels depending upon the pressing time (duration) and pressure applied: a) explicit form, and b) optimal value. 
Improved (lower) WA of the panels was clearly evidenced after increasing the pressure and pressing time. The WA of the laboratory-produced fibreboards varied from 48.85 to $70.95 \%$, a variation of 1.45 times was recorded. Pressure, greater than $4.25 \mathrm{MPa}$, had a stronger effect on the WA values. Stronger impact of the pressing time on the WA values was determined at values exceeding $310 \mathrm{~s}$. However, further increase of the pressing time above $340 \mathrm{~s}$ did not result in lower WA values. WA is not a standardized technical property, hence, the limits related to the other physical and mechanical properties of the panels, were set in Fig. 6b. As seen in Fig. 6, hardboards, meeting the standard requirements, can be produced at a minimum pressure of $4.6 \mathrm{MPa}$ and a pressing time of at least $375 \mathrm{~s}$. The minimum pressing time for producing hardboards was $280 \mathrm{~s}$ at a minimum pressure of $5.3 \mathrm{MPa}$. According to the statistical analysis, the optimal WA value of $48.12 \%$ was projected at a pressure of $5.3 \mathrm{MPa}$ and a pressing time of $353 \mathrm{~s}$.

\section{CONCLUSIONS}

Hardboards with acceptable physical and mechanical properties according to the EN standards may be produced from $60 \%$ poplar wood waste and residues, combined with $40 \%$ hardwood raw materials (beech and oak) by regulating the hot pressing regime only, i.e. pressure and pressing time. This facilitates the utilization of residual wood, which is a rather cyclical and irregular process, i.e. the addition of poplar in the composition of hardboards can be successfully implemented when sufficient amount of residual wood and waste is accumulated. The pressure applied had a significantly greater effect on all physical and mechanical properties of the laboratory-produced panels compared to the pressing time. The study revealed that at press temperature of $200^{\circ} \mathrm{C}$ the pressing time should not exceed 320 s. Otherwise, a deterioration of the strength properties of the panels was determined. The minimum regime parameters for producing hardboards from mixed hardwood tree species were: a pressure of 4.6 MPa and a pressing time of $280 \mathrm{~s}$.

\section{ACKNOWLEDGMENTS}

This research was supported by the projects No. НИС-Б-1002/03.2019 'Exploitation Properties and Possibilities for Utilization of Eco-friendly Bio-composite Materials', No. НИС-Б-1145/04.2021 'Development, Properties and Application of Eco-Friendly Wood-Based Composites' implemented at the University of Forestry, Sofia, Bulgaria, and projects by the Slovak Research and Development Agency under contracts No. APVV-18-0378, APVV-19-0269 and VEGA1/0717/19.

\section{REFERENCES}

1. Antov, P., Krišták, L., Réh, R., Savov, V., Papadopoulos, A.N., 2021a: Eco-friendly fiberboard panels from recycled fibres bonded with calcium lignosulfonate. Polymers 13(4): 639.

2. Antov, P., Mantanis, G.I., Savov, V., 2020a: Development of wood composites from recycled fibres bonded with magnesium lignosulfonate. Forests 11(6): 613.

3. Antov, P., Savov, V., Krišták, L., Réh, R., Mantanis, G.I., 2021b: Eco-friendly, high-density fiberboards bonded with urea-formaldehyde and ammonium lignosulfonate. Polymers 13(2): 220. 
4. Antov, P., Savov, V., Mantanis, G. I., Neykov, N., 2021c: Medium-density fibreboards bonded with phenol-formaldehyde resin and calcium lignosulfonate as an eco-friendly additive. Wood Material Science and Engineering 16(1): 42-48.

5. Antov, P., Savov, V., Neykov, N., 2020b: Sustainable bio-based adhesives for eco-friendly wood composites - a review. Wood Research 65(1): 51-62.

6. Bajpai, P., 2015: Generation of waste in pulp and paper mills. In: Management of Pulp and Paper Mill Waste. Pp 9-17, Springer, Berlin/Heidelberg, Germany.

7. Bekhta, P., Sedliačik, J., 2019: Environmentally-friendly high-density polyethylene-bonded plywood panels. Polymers 11(7): 1166.

8. Bekhta, P., Sedliačik, J., Kačík, F., Noshchenko, G., Kleinová, A., 2019: Lignocellulosic waste fibers and their application as a component of urea-formaldehyde adhesive composition in the manufacture of plywood. European Journal of Wood and Wood Products 77: 495-508.

9. Carvalho, L., Costa, C., 2003: A global model for the hot-pressing of MDF. Wood Science and Technology 37: 241-258.

10. EN 317, 1998: Particleboards and fibreboards. Determination of swelling in thickness after immersion in water.

11. EN 310, 1999: Wood-based panels. Determination of modulus of elasticity in bending and of bending strength.

12. EN 323, 2001: Wood-based panels. Determination of density.

13. EN 622-2, 2004: Fibreboards. Specifications. Part 2: Requirements for hardboards.

14. EN 316, 2009: Wood fibreboards. Definition, classification and symbols.

15. Ferdosian, F., Pan, Z., Gao, G., Zhao, B., 2017: Bio-based adhesives and evaluation for wood composites application. Polymers 9(2): 70.

16. Frihart, C.R., 2005: Wood adhesion and adhesives. In: Handbook of wood chemistry and wood composites (ed. Rowell, RM). Pp 214-278, CRC Press, Boca Raton, FL, USA.

17. González-García, S., Feijoo, G., Heathcote, C., Kandelbauer, A., Moreira, M.T., 2011: Environmental assessment of green hardboard production coupled with a laccase activated system. Journal of Cleaner Production 19(5): 445-453.

18. González-García, S., Feijoo, G., Widston, P., Kandelbauer, A., Zikulnig-Rusch, E., Moreira, M.T., 2014: Environmental performance assessment of hardboard manufacture. International Journal of Life Cycle Assessment 14: 456-466.

19. Gul, W., Khan, A., Shakoor, A., 2017: Impact of hot pressing temperature on medium density fiberboard (MDF) performance. Advances in Materials Science and Engineering, article ID 4056360, 6 pp.

20. Gupta, A., 2007: Modeling and optimization of MDF hot pressing. $\mathrm{PhD}$ thesis at the University of Canterbury, $196 \mathrm{pp}$.

21. Hosseinpourpia, R., Adamopoulos, S., Mai, C., Taghiyari, H. R., 2019: Properties of medium-density fiberboards bonded with dextrin-based wood adhesives. Wood Research 64(2): 185-194 pp.

22. Ihnát, V., Boruvka, V., Lubke, H., Babiak, M., Schwartz, J., 2015: Straw pulp as a secondary lignocellulosic raw material and its impact on properties of properties of insulating fiberboards. Part III. Preparation of insulating fiberboards from separately milled lignocellulosic raw materials. Wood Research 60(3): 457-466.

23. Ihnát, V., Lubke, H., Balberčák, J., Kuňa, V., 2020: Size reduction downcycling of waste wood. Review. Wood Research 65(2): 205-220. 
24. Ihnát, V., Lubke, H., Russ, A., Pažitný, A., Borůvka, V., 2018: Waste agglomerated wood materials as a secondary raw material for ( hipboards and fibreboards. Part II: Preparation and characterization of wood fibres in tern s of their reuse. Wood Research 63(3): 431-442.

25. Kumar, R.N., Pizzi, A., 2019: Envi: onmental aspects of adhesives - emission of formaldehyde. In: Adhesives for worid and lignocellulosic materials. Pp 293-312, Wiley-Scrivener Publishing, Hoboken, NJ USA.

26. Lubke, H., Ihnát, V., Kuňa, V., Balk erčák, J., 2020: A multi-stage cascade use of wood composite boards. Wood Researclı 65(5): 843-854.

27. Lubis, M.A.R., Hong, M.K., Park, B.D., 2018a: Hydrolytic removal of cured urea-formaldehyde resins in medium-den sity fiberboard for recycling. Journal of Wood Chemistry and Technology 38(1): 1-14.

28. Lubis, M.A.R., Hong, M.K., Park, B.D., Lee, S.M., 2018b: Effects of recycled fiber content on the properties of medium density fibreboard. European Journal of Wood and Wood Products 76: 1515-1526.

29. Lubis, M.A.R., Park, B.D., Hong, M.K., 2020: Tuning of adhesion and disintegration of oxidized starch adhesives for the recycling of medium density fiberboard. BioResources 15(3): 5156-5178.

30. Mantanis, G.I., Athanassiadou, E.T., B:rbu, M.C., Wijnendaele, K., 2018: Adhesive systems used in the European particleboard, MDF and OSB industries. Wood Material Science and Engineering 13: 104-116.

31. Neykov, N. Trichkov, N., Koynov, D., 2014: Functional-based and activity-based cost management systems in woodwo king enterprises. Specific and perspectives for implementation. Innovation in Woodv rorking Industry and Engineering Design 1(5): 161-165.

32. Neykov, N., Antov, P., Popova, R., 2018: Competitiveness of woodworking industries in the Balkan countries. Comparative advantages. Eastern European Business and Economics Journal 4(2): 132-142.

33. Neykov, N., Antov, P., Savov, V., 2020a: Circular economy opportunities for economic efficiency improvement in wood-based panel industry. In: Proceedings of the 11th International Scientific Conference "Business and Management 2020". Pp. 8-17, May 7-8, Vilnius, Lithuania.

34. Neykov N., Kitchoukov E., Simeonova-Zarkin T., Halalisan AF., 2020b: Economic efficiency estimation of innovations in combined forestry and wood processing units in Bulgaria through certification in FSC chain of custody. In: Innovation in sustainable management and entrepreneurship (ed. Prostean G, Lavios Villahoz J, Brancu L, Bakacsi G). Pp 695-703, SIM 2019. Springer Proceedings in Business and Economics, Springer, Cham.

35. Nordström, E., Demircan, D., Fogelström, L., Khabbaz, F., Malmström, E., 2017: Green binders for wood adhesives. In: Applied adhesive bonding in science and technology. Pp 47-71, Interhopen Books. London.

36. Papadopoulou, E., 2009: Adhesives from renewable resources for binding wood-based panels. Journal of Environmental Protection and Ecology 10: 1128-1136.

37. Papadopoulos, A.N., 2020a: Advances in wood composites. Polymers 12(1): 48.

38. Papadopoulos, A.N. 2020b: Advances in wood composites II. Polymers 12(7): 1552.

39. Pizzi, A., 2006: Recent developments in eco-efficient bio-based adhesives for wood bonding: opportunities and issues. Journal of Adhesion Science and Technology 20: 829-846. 
40. Pizzi, A., 2017: Wood and fiber panels technology. In: Lignocellulosic fibers and wood handbook: Renewable materials for to-day's environment (ed. Belgacem MN, Pizzi A). Chapter 15. Pp 385-406, Scrivener-Wiley, Beverley, MA, USA.

41. Pizzi, A., Papadopoulos, A.N., Policardi, F., 2020: Wood composites and their polymer binders. Polymers 12(5): 1115.

42. Rammou, E., Mitani, A., Ntalos, G., Koutsianitis, D., Taghiyari, H.R., Papadopoulos, A.N., 2021: The potential use of seaweed (Posidonia oceanica) as an alternative lignocellulosic raw material for wood composites manufacture. Coatings 11(1): 69.

43. Réh, R., Igaz, R., Krišták, L., Ružiak, I., Gajtanska, M., Božíková, M., Kučerka, M., 2019: Functionality of beech bark in adhesive mixtures used in plywood and its effect on the stability associated with material systems. Materials 12(8): 1298.

44. Russ, A., Schwartz, J., Boháček, Š., Lübke, H., Ihnát, V., Pažitný, A., 2013: Reuse of old corrugated cardboard in constructional and thermal insulating boards. Wood Research 58(3): 505-510.

45. Santoso, M., Widyorini, R., Prayitno, T.A., Sulistyo, J., Hamidah, N., 2020: Effect of pressing temperatures on bonding properties of sucrose-citric acid for nipa palm fronds particleboard. Wood Research 65(5): 747-756.

46. Schneider, T., Behn, C., Windeisen-Holzhauser, E., Roffel, E., 2019: Influence of thermo-mechanical and chemo-thermo-mechanical pulping on the properties of oak fibres. Holz als Roh- und Werkstoff 77(2): 229-234.

47. Shulga, G., Neiberte, B., Verovkins, A., Jaunslavietis, J., Shakels, V., Vitolina, S., Sedliačik, J., 2016: Eco-friendly constituents for making wood-polymer composites. Key Engineering Materials 688: 122-130.

48. Smith, D.C., 2004: The generation and utilization of residuals from composite panel products. Forest Products Journal 54: 8-17.

49. Taghiyari, H.R., Esmailpour, A., Majidi, R., Morrell, J.J., Mallaki, M., Militz, H., Papadopoulos, A.N., 2020: Potential use of wollastonite as a filler in UF resin based medium-density fiberboard (MDF). Polymers 12(7): 1435.

50. Tikhonova, E., Lecourt, M., Irle, M., 2014: The potential of partial substitution of the wood fibre in hardboards by reject fibres from the paper recycling industry. European Journal of Wood and Wood Products 72: 177-184.

51. Tritchkov, N., Antov, P., 2005: Prospects for developing the production of solid wood products taking into account the raw-material base. In: Proceedings of the COST Action E44 Conference broad spectrum utilisation of wood, issue 9. Pp 131-138, June 14-15, Vienna, Austria.

52. Tudor, E.M., Barbu, M.C., Petutschnigg, A., Réh, R., Krišták, L., 2020a: Analysis of larch-bark capacity for formaldehyde removal in wood adhesives. International Journal of Environmental Research and Public Health 17(3): 764.

53. Tudor, E.M., Dettendorfer, A., Kain, G., Barbu, M.C., Réh, R., Krišták, L., 2020: Sound-absorption coefficient of bark-based insulation panels. Polymers 12(5):1012.

54. Widsten P., Kandelbauer., A., 2014: Industrial scale evaluation of cationic tannin as a binder for hardboard. Journal of Adhesion Science and Technology 28(13): 1256-1263.

55. Widsten, P., Hummer, A., Heathcote, C., Kandelbauer, A., 2009: A preliminary study of green production of fiberboard bonded with tannin and laccase in a wet process. Holzforschung 63: 545-550.

56. Youngquist, J.A., 1999: Wood-based composites and panel products. In: Wood handbook: wood as an engineering material. Pp 1-31, USDA Forest Service, Forest Products Laboratory, Madison, WI, USA. 
Petar Antov*, Viktor Savov

University Of Forestry

Faculty Of Forest Industry

Department Of Mechanical Wood Technology

10 Kliment Ohridski BLVD.

I797 Sofia

Bulgaria

"Corresponding author: p.antov@ltu.bg

L'uboš KrišŤÁK

Faculty Of Wood Sciences And Technology

Technical University In Zvolen

960 or Zvolen

SLOVAKIA

Nikolay Neykov

University Of Forestry

Faculty Of Business Management

10 Kliment Ohridski BLVD.

I797 Sofia

Bulgaria 
